\title{
Comparison of affective perception by country for emerging IT products and services
}

\section{Hyun K. Kim}

School of Information Convergence,

Kwangwoon University, South Korea

Email: hyunkkim@kw.ac.kr

\section{Suhwan Jung and Jaehyun Park*}

Department of Industrial and Management Engineering, Incheon National University (INU), South Korea

Fax: +82-32-835-0777

Email: suhwan94@inu.ac.kr

Email: jaehpark@inu.ac.kr

*Corresponding author

\section{Ari Widyanti}

Department of Industrial Engineering,

Bandung Institute of Technology (ITB), Indonesia

Email: widyanti@ti.itb.ac.id

\begin{abstract}
Affective engineering research on products and services has been actively conducted, but there is little research on affect regarding newly emerging information technology products and services and analysis of cultural differences by country. This study used network analysis to collect the major affective vocabulary of individuals in the USA, China, Indonesia, Korea, and Russia for emerging IT products and services, and thereby analysed cultural differences. Affective vocabulary was collected related to virtual reality devices, fitness trackers, drones, a call taxi service, mobile pay, and virtual currency. Vocabulary collected through a survey was categorised into major affective vocabulary through network analysis. Social awareness of products/ services was confirmed through analysis of the positive/negative aspects of the vocabulary. The affect of the target IT products/services was compared and interpreted with reference to Hofstede theory. The results of this study may be used as a basis for the development of IT products and services.
\end{abstract}

Keywords: affective perception; semantic network analysis; SNA; IT products; IT services; cultural differences; Hofstede.

Reference to this paper should be made as follows: Kim, H.K., Jung, S., Park, J. and Widyanti, A. (2021) 'Comparison of affective perception by country for emerging IT products and services', Int. J. Mobile Communications, Vol. 19, No. 3, pp.387-411.

Biographical notes: Hyun K. Kim is an Assistant Professor in the School of Information Convergence at Kwangwoon University. She received her BS degree and $\mathrm{PhD}$ degree in Industrial and Management Engineering from 
POSTECH (Pohang University of Science and Technology). Her research interests are human-AI interaction, accessibility, and user experience.

Suhwan Jung received his MS degree in Industrial and Management Engineering at Incheon National University. His research interests include human-computer interaction, and network analysis.

Jaehyun Park is an Associate Professor in the Department of Industrial and Management Engineering at the Incheon National University. He received his $\mathrm{BS}$ and $\mathrm{PhD}$ in Industrial and Management Engineering from the Pohang University of Science and Technology (POSTECH). His research interests are human-computer interaction, user experience and user value.

Ari Widyanti is an Associate Professor in the Department of Industrial Engineering, Bandung Institute of Technology (ITB), Indonesia. She earned bachelor and master degrees from ITB, and $\mathrm{PhD}$ degree from University of Groningen, the Netherlands. Her research interest includes cognitive ergonomics and usability engineering.

\section{Introduction}

For information technology (IT) products and services to be successful in the market, the user's impression of them is critical; that is, affect is an important factor (Schütte, 2005; Park et al., 2013a, 2013b; Kim et al., 2015). The affect of users influences their intention to purchase the product/service, and affective perception is particularly related to loyalty, recommending the product to others, satisfaction with the product, and enhanced user experience (Chaudhuri, 1997; Bei and Chiao, 2001; Pullman and Gross, 2004; Fan et al., $2017 \mathrm{~b}$ ). One of the primary purposes of affective research is to create more satisfying products and services (Nagamachi, 1995), which leads to more purchases and repurchases (Seiders et al., 2005). To date, affective research has been conducted regarding automobiles (Lisetti and Nasoz, 2005; Katsis et al., 2008), mobile devices (Kim et al., 2016; Elhai et al., 2016), electronic products (Han et al., 2001; Chuang and Ma, 2001), and clothing (Kwon, 1994; Moody et al., 2010). Affect-related research has been predominately limited to products and services that have been commercially available for a long time; research into new and emerging IT products and services is relatively limited.

With the development of hardware and software technologies, IT products and services are emerging and disappearing faster than ever before. Examples include IT products (extinct products include smart TV and smart glass), 2D social network services (extinct products include Myspace classic), and web service the IT product smart TV was launched in anticipation of expanding the TV market, in a similar manner to smartphones and tablet PCs, but it did not achieve the expected results (Shin et al., 2015). Google's smart glass left the market shortly after its release, due to privacy infringement problems that were not solved (Hong, 2013; Due, 2014). The music-focused 2D social networking service Myspace was the world's most popular social networking site until early 2008. However, with the advent of Facebook, the popularity of Myspace classic declined and the site eventually disappeared (DeWolfe et al., 2003-2005). There is an ongoing process whereby various types of web services are newly introduced and modified to promote 
positive user affect, and then eliminated by competition (Bar-Ilan and Peritz, 2004). New IT products and services are required to continue to gain popularity to survive in the marketplace; as such, research into user affect is essential, and constant change must be pursued accordingly.

Consumer affect is driven by the consumer's interaction with the product/service in a culturally dependent manner (Furrer et al., 2000; Ko et al., 2004; Kim et al., 2010). Because IT products and services are no longer sold exclusively to specific countries but are spread around the world, it is very important to recognise cultural differences in targeted international markets (Mehta et al., 2006; Efrat, 2014; Fan et al., 2017a; Song et al., 2019). Several studies have assessed cultural preferences for widely commercialised IT products/services. Kim and Lee (2005) suggested that for smartphones, a global product, it is necessary to develop an interface that appropriately reflects the characteristics of cultures. Their study assessed user interface (UI) elements of smartphones that are thought to be influenced by culture. The study found out that Korean users performed better on concrete icon design than American users. Shin and Choo (2012) compared differences in perceptions of smartphones in South Korea and the USA and it was suggested that in the global marketing of products, cross-cultural strategies should be chosen. Harris et al. (2005) compared differences in user experience (UX) for M-commerce services in the UK and Hong Kong, confirming that attitudes to services differ from country to country depending on cultural and structural factors. In the same context as these studies, researches that analysed new IT products and services from a cultural point of view are needed.

This study consisted of affective research on three IT products [a virtual reality (VR) device, a fitness tracker, and a drone] and three IT services (a call service, mobile pay, and virtual currency). The reasons for choosing these products and services are they are

1 emerging products and services

2 they are relatively new IT products/services that had been on the market for more than one year

3 products and services that are considered highly likely to develop in the future.

This study collected affective vocabulary regarding the corresponding IT products and services in five countries (the USA, China, Indonesia, Korea, and Russia). The collected vocabulary was refined through semantic network analysis (SNA) and positive and negative classifications, and the core affective vocabulary for each product/service was derived. The key affective vocabulary derived by country was additionally analysed using Hofstede (1980) theory.

\section{Literature review}

\subsection{Affective engineering}

Emotion and affect have long been studied in the field of psychology. Emotion refers to a variety of psychological, mental experiences that humans feel (Cabanac, 2002). Emotion has a considerable impact on the individual, from memories to decisions (Barlow and Maul, 2000). In the 21 st century, emotional responses to products/services are used to evaluate and develop existing products and new products (Desmet, 2003). In addition, 
since the emergence of social media and commercial websites, it is becoming increasingly important to get emotion and opinions from users. Affect is very similar to emotion in that it is a psychological aspect of an individual. However, affect denotes the various feelings users obtain from using products and services, whereas emotion is different in that it refers to internal feelings that may be caused by numerous factors (Kim et al., 2016). This study was based on the concept of affect rather than emotion because it identified people's perceptions of products and services.

The type of affect generated by products and services has a significant impact on users' interactions with these items (Schütte, 2005; Kim et al., 2015; Park et al., 2013a, $2013 b$ ). That is, a study of the effects of consumer's feelings about products and services is needed to design products and services that can make a good impression on people. To systematically study affect, affect engineering was developed, which combines the study of affect with the methods of engineering (Nagamachi, 2016).

Affective engineering attempts to consumer-orient when developing products and services by considering the various types of affect that users express toward products and services (Nagamachi, 1995). These affects are defined in three categories: primitive affect, descriptive affect, and evaluative affect (Kim et al., 2016). Primitive affect refers to the relatively objective affect that arises as a result of the interaction of the consumer with the product/service. Descriptive affect denotes the added effect of subjectivity, which combines the user's individuality with his or her past experience with relevant products/services. Evaluative affect is the most subjective user assessment of the product/service. The interaction between user affect and products/services has been referred to as 'user value' in specific studies (Park and Han, 2013; Park et al., 2015; Lee and Park, 2018; Park and Han, 2018). The purpose of this study is to grasp the user's subjective opinion about IT products and services. Therefore, the concept of the evaluative affect was used in the study.

\subsection{Network analysis}

In order to identify the linkage pattern of keywords for IT devices and services, we used SNA to analyse the data. SNA is a method of identifying meaningful connections among entities that occur in complex network patterns (Van Atteveldt, 2008). SNA presents the relationships among people or activities in a network through the relationships among keywords that appear in the complex network. These features can be used to analyse online social platforms such as Facebook (Erétéo et al., 2009). SNA can be used to formulate new knowledge and to support various analyses through the search for keywords and mutual influence between keywords; the method is also being combining with cultural context (Stohl, 1993; Drieger, 2013; Rhie et al., 2017). In this study, recently, SNA has also been used to identify the fundamental causes of various problems that arise to identify people's perceptions. Li et al. (2018) investigated different party's perceptions of fuel cycle risks. Moro et al. (2020) used Facebook to mining consumers' comments from their posts and extracting important vocabularies through text mining. Kim and Jang (2018) used SNA to compare different expert groups' perceptions of the national scientific agenda. Kim and Ju (2019) applied SNA to analyse people's perspectives on IT from the textual data of blogs. 


\subsection{Cultural differences}

Various studies of cultural differences have been conducted (Hofstede, 1980; Hampden-Turner and Trompenaars, 2001; Scholz et al., 2002; House et al., 2004). Of these, Hofstede theory is the most widely used analytical tool (Kirkman et al., 2006; Sheldon et al., 2020). Hofstede theory was derived via an analysis of cultural differences in IBM employees across countries worldwide in the 1970s. Each country is divided into six dimensions [power distance, individualism, masculinity, uncertainty avoidance, long-term orientation, and indulgence (Hofstede, 1980)].

Figure 1 Evaluations for five countries, as defined by Hofstede

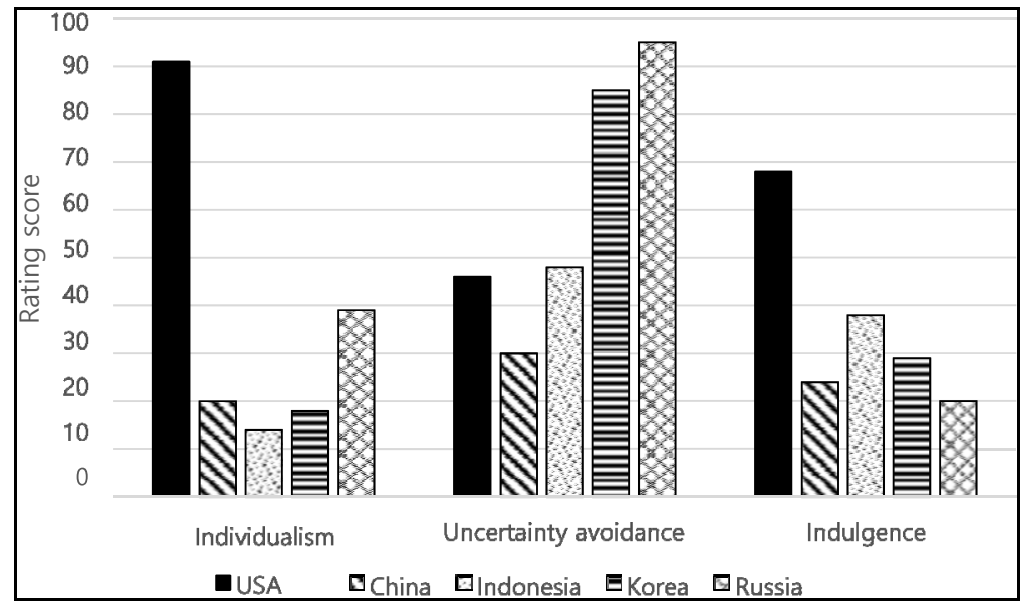

Since the Hofstede analysis was conducted in the 1970s, there have been concerns that the scores for each country might have changed over time (McSweeney, 2009; Tung and Verbeke, 2010). The current study, applied measures that have changed over time but have not changed relative to each country (indulgence and individualism), and a measure known to be less varied over time (uncertain avoidance). The three scales are as follows.

- Individualism: A measure of the degree of interdependence that society maintains among its members.

- Uncertainty avoidance: A measure of the degree of anxiety about unknown future situations.

- Indulgence: The degree to which members of a society try to control their desires and impulses.

Figure 1 shows Hofstede evaluation scores for each country (the USA, China, Indonesia, Korea, and Russia) on three scales [indulgence, individualism and uncertainty avoidance (Hofstede, 1980)]. Each score falls on a 0-100 scale, while the scale midpoint (50 points) is used to divide the tendencies of each country. For example, in individualism in Figure 1, the scores of China, Indonesia, Korea, and Russia are less than 50; as such, they are defined as countries with strong collectivism tendencies. In contrast, the score for the USA is more than 50; accordingly, it is defined as a country with a strong tendency toward individualism. 


\section{Method}

\subsection{Participants}

Participants consisted of 33 American students at Texas A\&M - Corpus Christi (19 men, 14 women; mean age $=25.1$ years, $\mathrm{SD}=12.3), 30$ Chinese students at Fudan University and Peking University (10 men, 20 women; mean age $=29.6$ years, SD = 7.02), 42 Indonesian students at Bandung Institute of Technology (29 men, 13 women; mean age $=22$ years, $\mathrm{SD}=3.4), 34$ Korean students at Incheon National University (23 men, 11 women; mean age $=24.5$ years, $\mathrm{SD}=1.5)$, and 31 Russian students at Samara State Technical University ( 25 men, 6 women; mean age $=20.7$ years, $\mathrm{SD}=2.3$ ).

\subsection{Target devices and services}

Affect was compared for three IT products (VR device, fitness tracker, and drone) and three IT services (call taxi service, mobile pay, and virtual currency). The selected products and services were required to meet three conditions:

1 emerging IT products and services

2 relatively new IT products/services that had been on the market for more than one year

3 products and services that are considered highly likely to develop in the future.

VR technology is currently attracting the attention of the enthusiast or hobbyist community and is being developed gradually by skilled technologists (Burdea and Coiffet, 2003). Several recent studies of VR exist, such as the development of indicators related to motion sickness in the VR environment (Kim et al., 2018), and the study of VR input devices (Choe et al., 2019). The core technology of fitness trackers is of great interest to users today and is a promising technology for the future (Bajpai et al., 2015; Wei and Kang, 2019). Regarding drones, more than 50 organisations have operational approval for drone use, and the number of users is increasing (Pasztor and Emshwiller, 2012). According to Gartner (Panetta, 2019), VR technology and drone were selected as the Gartner Top 10 strategic technology trends for 2020.

With respect to call taxi service and mobile pay, many people are familiar with previous methods, such that these services are not yet popular. However, these services are becoming simpler and more convenient, and consequently more popular, particularly with the millennial generation (Straus and Howe, 1991; Williams, 2014). The virtual currency has become known to people relatively recently, in a virtual form called 'Bitcoin'. Virtual currency is a service based on blockchain technology, which is attracting attention due to its high efficiency and impact (Swan, 2015; Crosby et al., 2016). According to Gartner (Panetta, 2019), blockchain was selected as the Gartner Top 10 strategic technology trends for 2020.

\subsection{Data collection}

Data were collected using the questionnaire shown in Figure 2. After translating the questionnaire into each national language, the same questions were asked of the participants. Translation and survey were conducted by a native human factor expert 
from the respective national university. First, to help users understand each product/ service, a definition of each was provided, along with an example of a current commercial product. The questionnaire asked for the following:

1 recognition of the product/service

2 experience with the product/service

3 duration of using the product/service

4 willingness to use the product/service

5 words related to the product/service

6 reasons for entering each word.

In step 5, users were encouraged to write down at least five impressions/images/words for each IT product and service.

Figure 2 Example of survey form (for VR device) (see online version for colours)

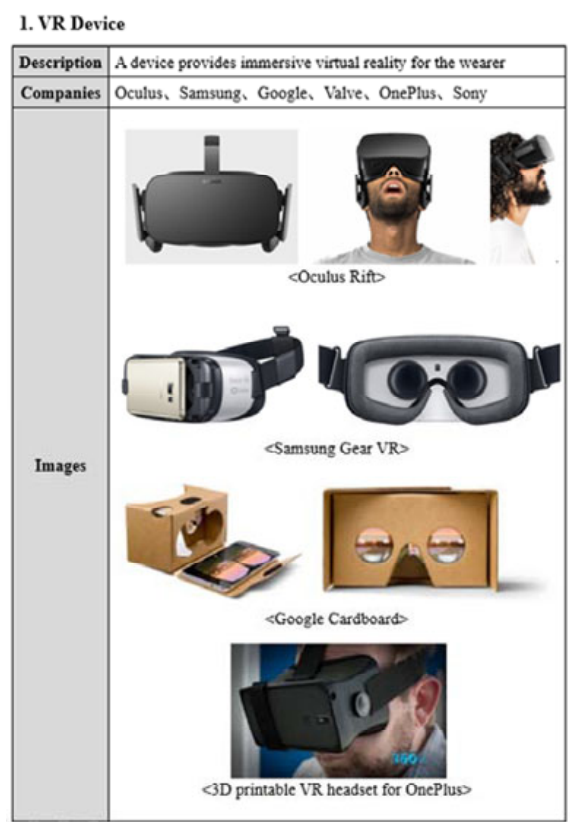

\begin{tabular}{|l|l|}
\hline 1-1. Product recognition & $\begin{array}{l}\text { a I already know what the product is } \\
\text { o I've never seen the product }\end{array}$ \\
\hline 1-2. Experience of use & $\begin{array}{l}\text { a I've ever used the product (go to 1-3) } \\
\text { o I haven't used the product (go to 1-4) }\end{array}$ \\
\hline 1-3. A device in use & $\begin{array}{l}\text { Which product you're currently using? ( } \\
\text { When did you buy the product? ( }\end{array}$ \\
\hline 1-4. Purchase intention & $\begin{array}{l}\text { a I'm willing to buy it, if the price is reasonable } \\
\text { I will not buy it }\end{array}$ \\
\hline
\end{tabular}

1-5. Please write down the associated word (more than 5 ) when viewing the products

\subsection{Analysis}

\subsubsection{Semantic network analysis}

After collecting words through the survey, the correlations between words were analysed. The languages collected by country were reviewed by three human factors experts and translated into consistent English. Network analysis was conducted using the correlations between the translated words. The key measures of the network analysis were degree centrality, eigenvector centrality, and edge weight. Degree centrality is defined by the number of connected nodes (word in this case) (Borgatti, 1995). As the number of people 
who report a node increases, the degree centrality score increases. In other words, a large degree of centrality score means that many people have responded. Eigenvector centrality is a measure of the degree of influence between nodes, which reflects the degree centrality of different nodes. Eigenvector centrality values increase as more nodes are connected, and as nodes with high degree centrality values are connected. Edge weight means the number of times that two words are answered simultaneously.

The top 20 nodes were extracted based on the degree centrality scores of the nodes. Among the selected nodes, those that satisfied the following conditions were additionally removed. First, if the names of products and services appeared in the selected vocabulary, they were deleted because they were not included considered affective words. Second, if degree centrality was relatively high, but eigenvector centrality was very small, then the word was deleted because it did not affect the correlations between words.

Two network programs were used to visualise the data analysis: Gephi-0.9.1 and UCINET. Gephi can visualise a large range of networks quickly and accurately, control various operations on the network in a simple manner (Bastian et al., 2009). UCINET has the advantage of easily expressing Excel data as a network relationship between cohesive subgroups (Borgatti et al., 2014).

\subsubsection{Affective vocabulary analysis}

Twenty Korean participants $(10$ men, 10 women; mean age $=22.9$ years, $\mathrm{SD}=1.5)$ classified the 235 unique words obtained from the five countries into three categories: positive, neutral, and negative. Neutral words represented non-affective vocabulary. Each word was classified based on the category for which it received the most responses. If the number of responses for positive or negative and neutral was the same, the word was considered as affective vocabulary. For example, the word 'sight' received ten positive and ten neutral responses. In this case, the word was defined as positive. For the word 'filming', six people answered positive and 14 people answered neutral. Therefore, the word was defined as neutral.

In addition, the ratios of positive, neutral, and negative words were analysed for each product/service in each country. Because the number of words extracted by country for each product/service was not constant, the following formula was used.

$(($ Positive, negative, or neutral frequency $) /($ total number of words $)) \times 100 \%$

Additionally, the following formula was used to calculate the ratio of affective vocabulary for each product/service in each country.

((Positive words + negative words) /

$($ positive words + neutral words + negative words $)) \times 100 \%$ 


\section{Results}

\subsection{Results of survey}

Table 1 shows the sum of the words generated by the participants of each country, without removing duplicate words within the country. Table 2 shows the average and standard deviation of the total number of words generated per participant.

Table 1 Overall number of words generated

\begin{tabular}{lccccccc}
\hline $\begin{array}{l}\text { Overall } \\
\text { word }\end{array}$ & $\begin{array}{c}\text { VR } \\
\text { device }\end{array}$ & $\begin{array}{c}\text { Fitness } \\
\text { tracker }\end{array}$ & Drone & $\begin{array}{c}\text { Call taxi } \\
\text { service }\end{array}$ & $\begin{array}{c}\text { Mobile } \\
\text { pay }\end{array}$ & $\begin{array}{c}\text { Virtual } \\
\text { currency }\end{array}$ & Total \\
\hline USA & 97 & 84 & 83 & 82 & 78 & 54 & 478 \\
China & 148 & 146 & 128 & 147 & 138 & 101 & 808 \\
Indonesia & 187 & 170 & 181 & 187 & 145 & 149 & 1,019 \\
Korea & 162 & 162 & 164 & 158 & 162 & 116 & 924 \\
Russia & 105 & 137 & 107 & 120 & 105 & 71 & 645 \\
\hline
\end{tabular}

Table 2 Average number words generated per participant

\begin{tabular}{lccccccc}
\hline $\begin{array}{l}\text { Overall } \\
\text { word }\end{array}$ & $\begin{array}{c}\text { VR } \\
\text { device }\end{array}$ & $\begin{array}{c}\text { Fitness } \\
\text { tracker }\end{array}$ & Drone & $\begin{array}{c}\text { Call taxi } \\
\text { service }\end{array}$ & $\begin{array}{c}\text { Mobile } \\
\text { pay }\end{array}$ & $\begin{array}{c}\text { Virtual } \\
\text { currency }\end{array}$ & Total \\
\hline USA & $2.9( \pm 2.5)$ & $2.5( \pm 2.4)$ & $2.5( \pm 2.5)$ & $2.5( \pm 2.3)$ & $2.4( \pm 2.3)$ & $1.6( \pm 2.2)$ & $2.4( \pm 2.4)$ \\
China & $4.9( \pm 1.2)$ & $4.9( \pm 1.1)$ & $4.3( \pm 1.7)$ & $4.9( \pm 0.7)$ & $4.6( \pm 0.9)$ & $3.4( \pm 1.9)$ & $4.5( \pm 1.4)$ \\
Indonesia & $4.5( \pm 0.8)$ & $4.0( \pm 1.2)$ & $4.3( \pm 0.9)$ & $4.4( \pm 1.0)$ & $3.5( \pm 1.6)$ & $3.5( \pm 1.5)$ & $4.0( \pm 1.2)$ \\
Korea & $4.8( \pm 1.0)$ & $4.8( \pm 0.9)$ & $4.8( \pm 1.0)$ & $4.6( \pm 1.0)$ & $4.8( \pm 1.2)$ & $3.4( \pm 2.0)$ & $4.5( \pm 1.3)$ \\
Russia & $3.4( \pm 1.9)$ & $4.4( \pm 1.4)$ & $3.6( \pm 1.5)$ & $3.9( \pm 1.5)$ & $3.4( \pm 1.6)$ & $2.3( \pm 1.9)$ & $3.5( \pm 1.7)$ \\
\hline
\end{tabular}

\subsection{Results of SNA}

Table 3 shows affective words with the highest degree centrality, the highest eigenvector centrality, and the affective word pair with the highest edge weight, by country and product/service, as obtained in the SNA.

Figures 3-8 show the visualisations generated using Gephi and UCINET for specific products/services by country and for all countries. The size of each node represents the magnitude of eigenvector centrality, and the thickness of the lines between nodes increases with the number of simultaneous occurrences of both words.

\subsection{Affective vocabulary analysis}

To determine the affective vocabulary collected in the five countries, words were classified as positive, neutral, and negative. Table 4 shows the classifications of the representative 10 out of 235 words, after removing duplicates. 
Table 3 Top affective vocabulary by country and product/service

\begin{tabular}{|c|c|c|c|c|}
\hline Country & $\begin{array}{l}\text { Product/service } \\
\text { name }\end{array}$ & $\begin{array}{l}\text { Max degree } \\
\text { centrality }\end{array}$ & $\begin{array}{l}\text { Max eigenvector } \\
\text { centrality }\end{array}$ & Max edge weight \\
\hline \multirow[t]{6}{*}{ Overall } & VR device & Expensive & Expensive & Expensive and cool \\
\hline & Fitness tracker & Health & Health & Health and expensive \\
\hline & Drone & Expensive & Expensive & Convenient and fast \\
\hline & Call taxi service & Convenient & Convenient & Fast and cheap \\
\hline & Mobile pay & Convenient & Convenient & Convenient and fast \\
\hline & Virtual currency & Safe & Safe & $\begin{array}{l}\text { Virtual and currency; } \\
\text { virtual and safe; virtual } \\
\text { and investment }\end{array}$ \\
\hline \multirow[t]{6}{*}{ USA } & VR device & Interesting & Interesting & Interesting and new \\
\hline & Fitness tracker & Fitness & Fitness & $\begin{array}{l}\text { Convenient and useful; } \\
\text { fitness and work-out; } \\
\text { useful and new }\end{array}$ \\
\hline & Drone & Fun & Fun & Fun and technology \\
\hline & Call taxi service & Convenient & Convenient & Convenient and safe \\
\hline & Mobile pay & Convenient & Convenient & $\begin{array}{c}X \text { (almost all edges are } \\
\text { the same) }\end{array}$ \\
\hline & Virtual currency & $\begin{array}{l}\text { Useful; } \\
\text { sketchy }\end{array}$ & Useful & $\begin{array}{l}\text { Useful and sketchy; useful } \\
\text { and convenient }\end{array}$ \\
\hline \multirow[t]{6}{*}{ China } & VR device & Technology & Technology & Expensive and frontier \\
\hline & Fitness tracker & Health & Health & $\begin{array}{l}\text { Exercise and trend; } \\
\text { practical and convenient; } \\
\text { light and convenient }\end{array}$ \\
\hline & Drone & Filming & Filming & $\begin{array}{c}X \text { (one-third of the edges } \\
\text { are the same) }\end{array}$ \\
\hline & Call taxi service & Convenient & Convenient & Convenient and fast \\
\hline & Mobile pay & Convenient & Convenient & Convenient and fast \\
\hline & Virtual currency & Virtual & Valuable & Bitcoin and mining \\
\hline \multirow[t]{6}{*}{ Indonesia } & VR device & Expensive & Expensive & Expensive and cool \\
\hline & Fitness tracker & Expensive & Expensive & Expensive and useless \\
\hline & Drone & Expensive & Expensive & Expensive and advanced \\
\hline & Call taxi service & Easy; cheap & Cheap & Fast and cheap \\
\hline & Mobile pay & Simple & Simple & Fast and easy \\
\hline & Virtual currency & Money & Money & $\begin{array}{c}\text { Money and safe; money } \\
\text { and expensive; money and } \\
\text { investment }\end{array}$ \\
\hline \multirow[t]{6}{*}{ Korea } & VR device & $3 \mathrm{D}$ & $3 \mathrm{D}$ & Movie and game \\
\hline & Fitness tracker & Health & Health & Health and exercise \\
\hline & Drone & $\begin{array}{l}\text { Helicopter; } \\
\text { delivery }\end{array}$ & $\begin{array}{l}\text { Helicopter; } \\
\text { delivery }\end{array}$ & $\begin{array}{l}\text { Filming and delivery; toy } \\
\text { and helicopter }\end{array}$ \\
\hline & Call taxi service & Convenient & Convenient & Convenient and safe \\
\hline & Mobile pay & Convenient & Convenient & Convenient and security \\
\hline & Virtual currency & Hacking & Hacking & Hacking and currency \\
\hline
\end{tabular}


Table 3 Top affective vocabulary by country and product/service (continued)

\begin{tabular}{lcccc}
\hline Country & $\begin{array}{c}\text { Product/service } \\
\text { name }\end{array}$ & $\begin{array}{c}\text { Max degree } \\
\text { centrality }\end{array}$ & $\begin{array}{c}\text { Max eigenvector } \\
\text { centrality }\end{array}$ & Max edge weight \\
\hline Russia & VR device & Game; & entertainment & Game; \\
entertainment & Movie and game \\
& Fitness tracker & Health & Health & Sport and watch \\
Drone & Entertainment & Entertainment & Entertainment and game \\
& Call taxi service & Comfort & Comfort & Comfort and quick \\
Mobile pay & Convenient; & Convenient & Smartphone and purchase \\
& Smartphone & Currency & Currency and internet \\
\hline
\end{tabular}

Figure 3 Semantic network among all countries for products and services

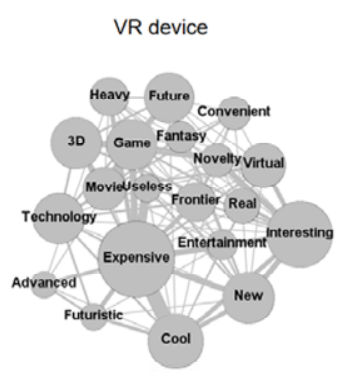

Call Taxi Service

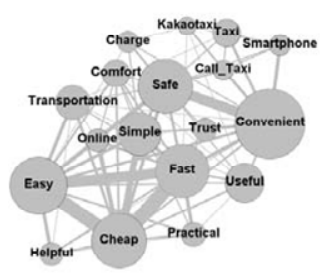

Fitness Tracker

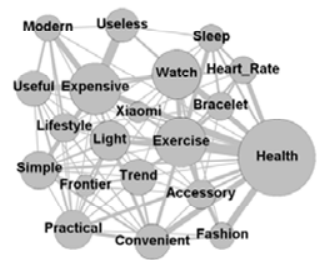

Mobile Pay

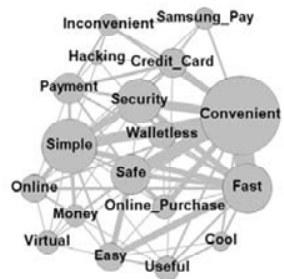

Drone

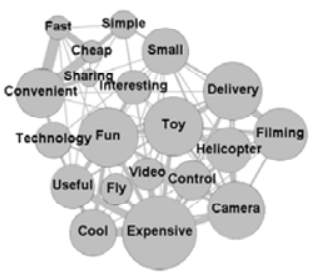

Virtual Currency

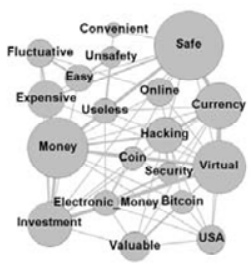

Table 4 Classifications of words as positive, neutral, or negative (10 out of 235 words shown)

\begin{tabular}{llcccc}
\hline Number & Name & Positive & Neutral & Negative & Result \\
\hline 1 & Filming & 6 & 14 & 0 & Neutral \\
2 & Control & 8 & 6 & 6 & Positive \\
3 & Distribution & 7 & 11 & 2 & Neutral \\
4 & Expensive & 1 & 2 & 17 & Negative \\
5 & Fun & 20 & 0 & 0 & Positive \\
6 & Small & 1 & 11 & 8 & Neutral \\
7 & Novelty & 14 & 6 & 0 & Positive \\
8 & Interesting & 20 & 0 & 0 & Positive \\
9 & Heavy & 0 & 6 & 14 & Negative \\
10 & Future & 15 & 5 & 0 & Positive \\
\hline
\end{tabular}


Figure 4 Semantic network for products and services assessed by Americans
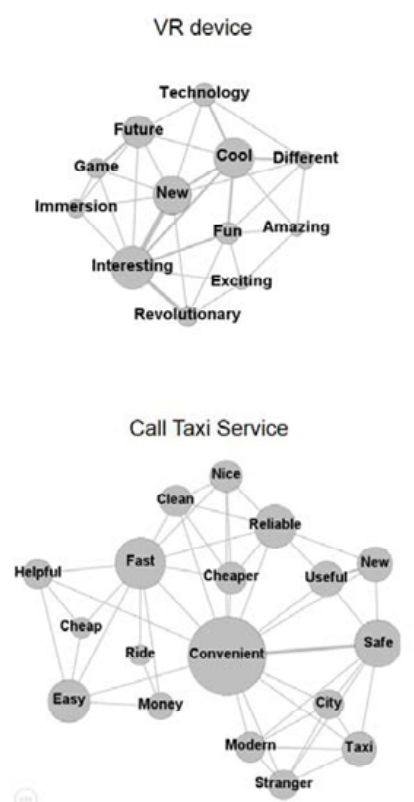

Fitness Tracker

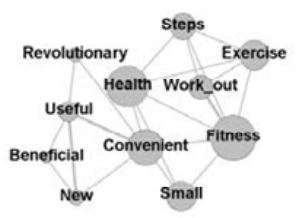

Mobile Pay

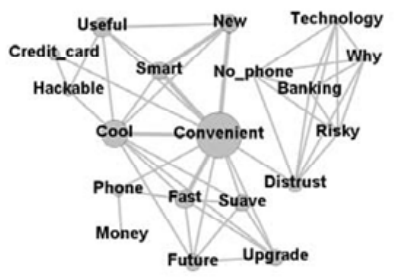

Drone

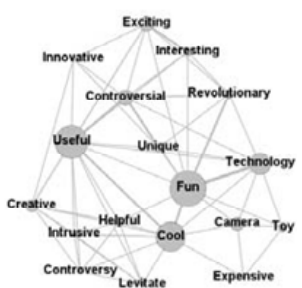

Virtual Currency

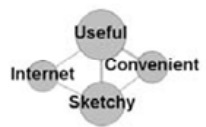

Figure 5 Semantic network for products and services assessed by Chinese individuals

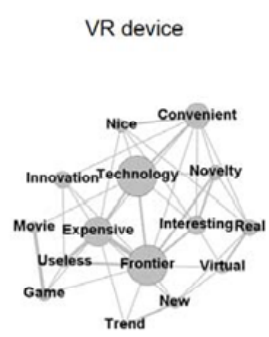

Call Taxi Service

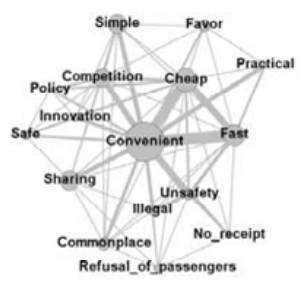

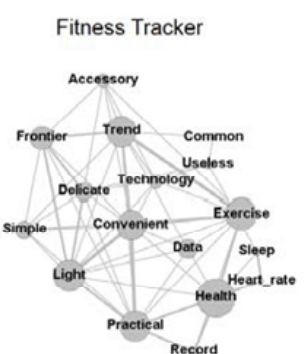

Mobile Pay

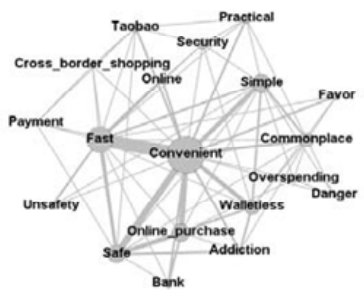

Drone

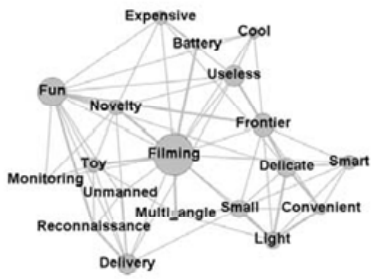

Virtual Currency

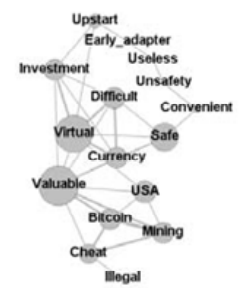

Figure 9 compares the number of positive, neutral, and negative words collected for each product/service by country. For example, for 'drone' in Korea, the number of words extracted by Gephi was 15. Of these, seven were positive words [i.e., $46.7 \%$ by equation (1)]. Figure 9 illustrates that people in China reported negative vocabulary for all product and service groups, whereas in Indonesia, negative vocabulary appeared for all products and service groups, except call taxi service. Four products/services were 
attributed to negative vocabularies in Korea: VR device, drone, mobile pay, and virtual currency. Russian individuals only assigned negative vocabulary to 'drone', and Americans only provided negative vocabulary for 'drone' and 'mobile pay'.

Figure 6 Semantic network for products and services assessed by Indonesians

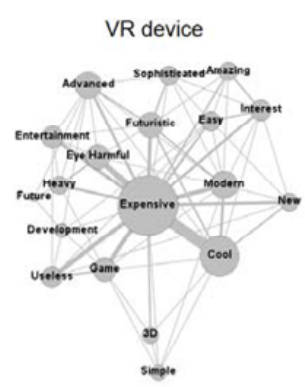

Call Taxi Service

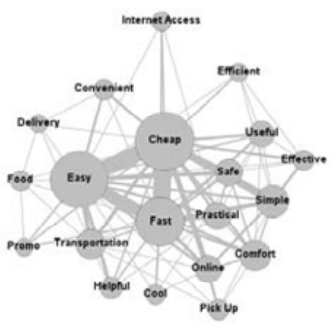

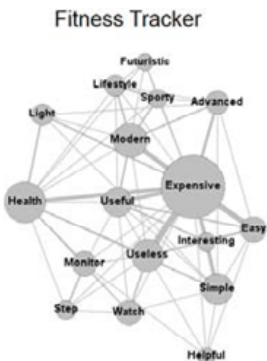

Mobile Pay

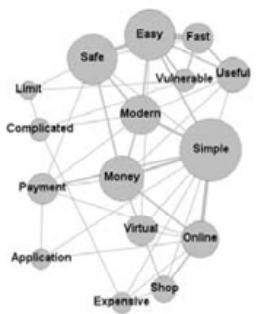

Drone

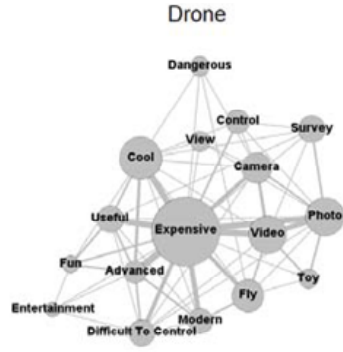

Virtual Currency

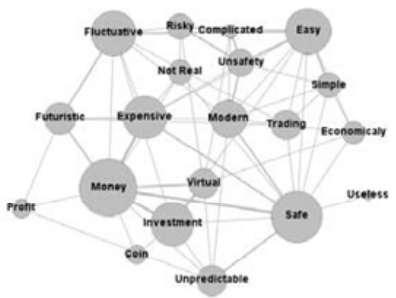

Figure 7 Semantic network for products and services assessed by Koreans

VR device

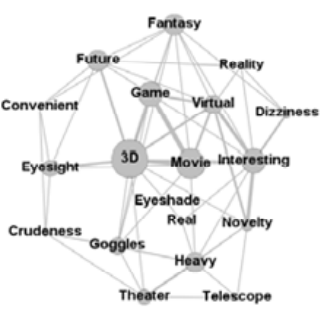

Call Taxi Service

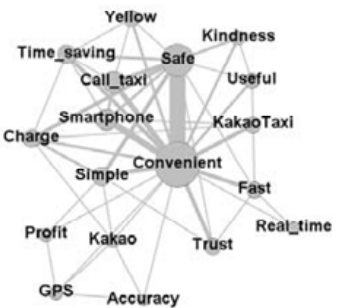

Fitness Tracker

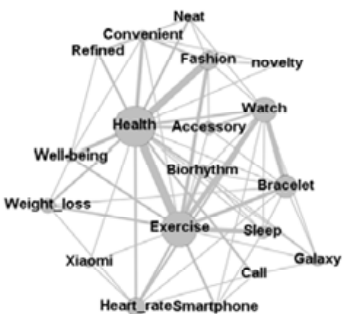

Mobile Pay

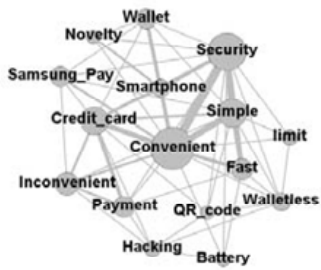

Drone

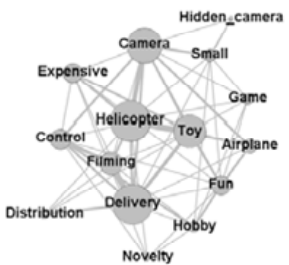

Virtual Currency

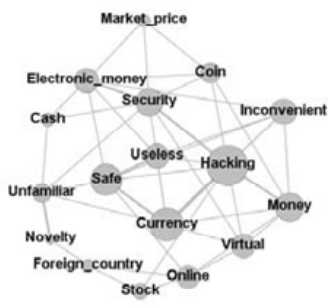

Figure 10 represents the proportion of the affective (positive and negative) vocabulary shown in Figure 9, using equation (2). The proportion of affective words decreased in the 
order of the USA, Russia, Indonesia, Korea, and then China. Table 5 shows the proportion of affective vocabulary for each product and service. The equation used to calculate the proportion was ((number of affective words in one country / sum of affective vocabulary among five countries $) \times 100 \%$. The table confirms which countries had a large proportion of affective vocabulary per product and service.

Figure 8 Semantic network for products and services assessed by Russians

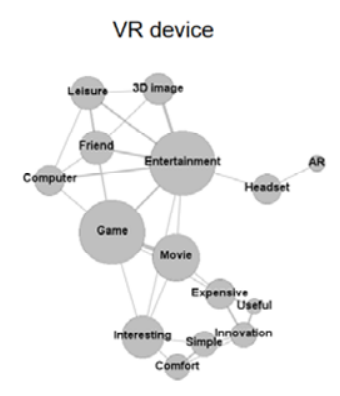

Call Taxi Service

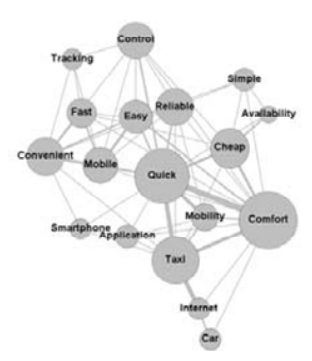

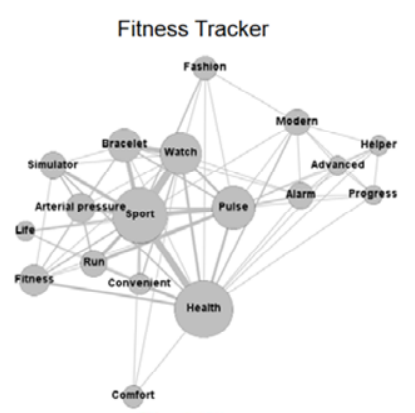

Mobile Pay

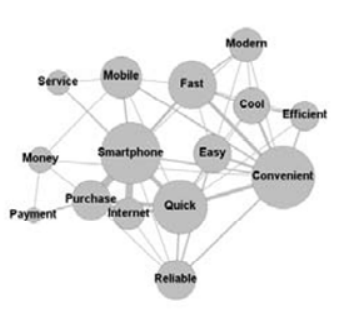

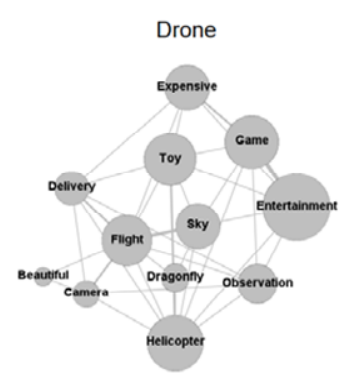

Virtual Currency

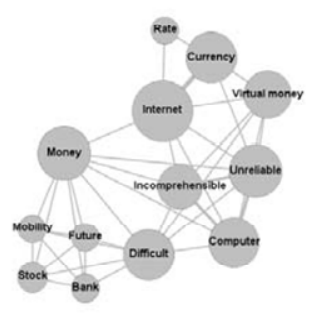

Figure 9 Proportions of positive, neutral, and negative vocabulary in five countries
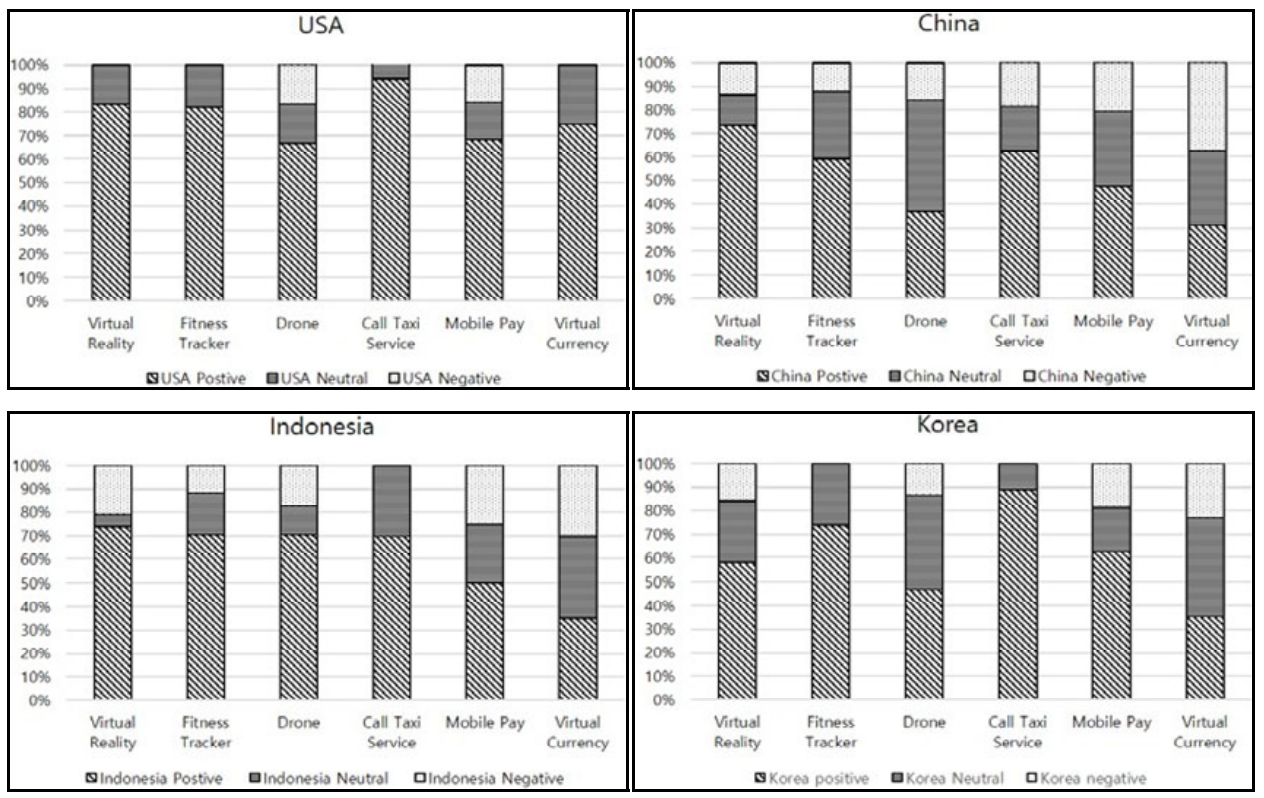
Figure 9 Proportions of positive, neutral, and negative vocabulary in five countries (continued)

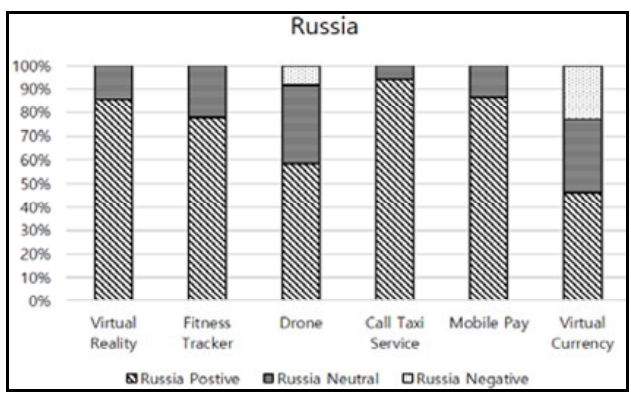

Figure 10 Comparison of affective vocabulary among five countries

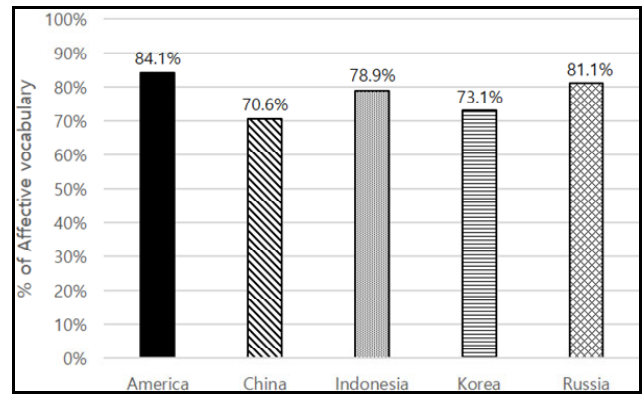

Table 5 Percentage of affective vocabulary per product and service

\begin{tabular}{lcccccc}
\hline & VR device & $\begin{array}{c}\text { Fitness } \\
\text { tracker }\end{array}$ & Drone & $\begin{array}{c}\text { Call taxi } \\
\text { service }\end{array}$ & Mobile pay & $\begin{array}{c}\text { Virtual } \\
\text { currency }\end{array}$ \\
\hline USA & $20 \%$ & $21 \%$ & $24 \%$ & $22 \%$ & $21 \%$ & $22 \%$ \\
China & $20 \%$ & $18 \%$ & $15 \%$ & $19 \%$ & $17 \%$ & $20 \%$ \\
Indonesia & $22 \%$ & $21 \%$ & $25 \%$ & $16 \%$ & $19 \%$ & $19 \%$ \\
Korea & $17 \%$ & $19 \%$ & $17 \%$ & $21 \%$ & $21 \%$ & $17 \%$ \\
Russia & $20 \%$ & $20 \%$ & $19 \%$ & $22 \%$ & $22 \%$ & $21 \%$ \\
\hline
\end{tabular}

\section{Discussion}

\subsection{General word analysis}

Figure 3 is the result of the analysis of affective vocabulary among all countries. First, in the case of VR device, the price was considered the most important issues, while most people perceived the product favourably. Additionally, there was high recognition that the product is innovative, as evidenced by the use of terms such as 'new', 'novelty', 'ingenuity', and so on. Second, fitness trackers were characterised as an expensive watch or an accessory related to health and exercise. Many words directly related to daily life were generated (e.g., 'lifestyle', 'health', and 'sleep'). Third, most people perceived drones as expensive but convenient and fast. The vocabulary was generated related to the functional characteristics of drones, such as 'filming', 'delivery', and 'camera' and to the 
appearance of drones, such as 'helicopter' and 'toy'. In summary, for the product group, the affective word 'expensive' commonly appeared. Fourth, for the call taxi service, 'convenient' showed the highest eigenvector, confirming the core affective vocabulary. In addition, the words 'fast', 'safe', 'easy', and 'cheap' were collected. Fifth, for mobile pay, the highest eigenvector was also for 'convenient'. Several words were generated regarding safety (e.g., 'security', 'hacking', and 'safe') and cost (e.g., 'payment', 'money', and 'credit card'), because these services are directly related to money. Finally, in the case of virtual currency, many words were generated regarding safety (e.g., 'unsafe', 'security', 'hacking', and 'safe') and cost (e.g., 'expensive' and 'money'), because these services are also directly related to money. To summarise the service group, safety and cost were greatly influential.

\subsection{Cultural comparison}

\subsubsection{American semantic network descriptions}

Figure 4 is the result of the analysis of affective vocabulary in the USA. First, for VR device, most of the American sample perceived it as an exciting new product. There were many words generated related to the usability of products (e.g., 'cool', 'fun', 'interesting', 'exciting', 'amazing', 'new', and 'revolutionary'). Second, most people perceived fitness trackers as useful and convenient products related to health and exercise. Unlike other countries, vocabulary related to the external characteristics of the product did not appear. There were many words generated related to the usability of products (e.g., 'useful', 'new', 'convenient', 'beneficial', and 'revolutionary') and affective words (e.g., 'fitness' and 'health'). Third, in the case of drones, most participants perceived them as interesting techniques. Unlike in other countries, many words were generated related to the usability (e.g., 'exciting', 'Interesting', 'cool', 'fun', 'creative', and 'useful') rather than to functional characteristics. In summary, for the product group, words related to the usability of the product were commonly found in the main affective vocabulary. Fourth, for the call taxi service and mobile pay, 'convenient' exhibited the highest eigenvector, confirming the core affective vocabulary. In addition, for call taxi service, the words 'fast', 'safe', and 'easy' were collected, and for mobile pay, the word 'cool' was generated. There were several words generated regarding safety (e.g., 'safe', 'distrust', 'risky', and 'hackable') and cost (e.g., 'cheap', 'money', and 'banking'), because these services are directly related to money. Finally, for virtual currency, the vocabulary was smaller than that for other products and services, which represents the service's unfamiliarity to Americans. In summary, for the service group, convenience was highly influential.

\subsubsection{China semantic network descriptions}

Figure 5 is the result of the analysis of affective vocabulary generated by people in China. First, for VR device, most Chinese individuals perceived it is a new, innovative, expensive, state-of-the-art technology product. Second, fitness trackers were generally perceived as convenient and trendy accessories related to health; many affective words directly related to life were generated (e.g., 'sleep', 'health'). Third, in the case of drones, most of the individuals perceived them as filming products. The vocabulary was generated related to the functional characteristics of drones, such as 'battery', 'delivery', 
and 'multi-angle', and to the appearance of drones, such as 'toy'. In summary, in the case of the product group, the Chinese participants attended to the advanced technology and confirmed that price reduction and improved function and appearance are important. Fourth, for the call taxi service and mobile pay, 'convenient' showed the highest eigenvector, confirming the core affective vocabulary. In addition, for the call taxi service, the words 'fast' and 'cheap' applied, and for mobile pay, 'fast' and 'safe' were collected. Several words regarding safety (e.g., 'safe', 'unsafe', and 'security') and cost (e.g., 'cheap', 'payment', and 'bank') were generated because these services are directly related to money. Finally, in the case of virtual currency, most individuals perceived this as a virtual, valuable service. Several words were generated regarding safety (e.g., 'safe', 'unsafe', and 'security') and cost (e.g., 'currency'), because these services are directly related to money. In summary, for the service group, safety and cost were considered important.

\subsubsection{Indonesia semantic network descriptions}

Figure 6 is the result of the analysis of affective vocabulary generated by Indonesians. In all three product groups, 'expensive' was collected as a core affective word. In addition, in the case of VR device and drone, the words 'cool' and 'advanced' were obtained, and for fitness trackers, 'health' was collected. In the case of the drone, words were generated related to functional characteristics, such as 'photo', 'camera', 'fly', and 'control', and to the appearance, such as 'toy'. Most products, and especially fitness trackers, were deemed expensive and useless accessories. For the call taxi service and mobile pay of the service group, core affective vocabulary consisted of 'easy', 'cheap', 'fast', 'simple', and 'safe'. Several words were generated with respect to safety (e.g., 'safe'), cost (e.g., 'cheap', 'money', and 'payment'), because these services are directly related to money. Finally, virtual currency is primarily an expensive investment type service; thus, many words were generated pertaining to safety (e.g., 'safe' and 'unsafe') and cost (e.g., 'expensive' and 'money'). For the service group, safety and cost were considered important; the Indonesian sample was very sensitive to price.

\subsubsection{Korea semantic network descriptions}

Figure 7 is the result of an analysis of affective vocabulary in Korea. First, for VR device, most Koreans perceived the product as a 3D game or movie. They also perceived this as an innovative product with fantasy and novelty aspects. Second, most perceived fitness trackers as a watch, bracelet, or accessory related to health and exercise. Many affective words were generated (e.g., 'sleep' and 'health') directly related to life. Third, in the case of drones, most individuals perceived them as toys or delivery helicopters. The vocabulary was generated related to the functional characteristics of the drone, such as 'camera', 'delivery', and 'control', and to drone appearance, such as 'helicopter' and 'toy'. Fourth, in the case of the call taxi service and mobile pay, 'convenient' showed the highest eigenvector, confirming the core affective vocabulary. In addition, 'safe' was assigned to the taxi service and 'security' and 'simple' to mobile pay. There were several words generated regarding safety (e.g., 'safe', 'security', 'trust', and 'hacking') and cost (e.g., 'charge', 'credit card', and 'payment'), because these services are directly related to money. Finally, most individuals perceived virtual currency as currency with a risk of hacking. The service was not familiar, as evidenced by words such as 'useless' and 
'foreign country'. There were many words generated regarding safety (e.g., 'safe', 'security', and 'hacking') and cost (e.g., 'money', 'cash', and 'market price'). In the case of the service group, safety and cost were considered important. In Korea, the major affective vocabulary was similar to that generated by the Chinese participants, although the frequency of safety-related vocabulary was higher in the Korean sample.

\subsubsection{Russia semantic network descriptions}

Figure 8 is the result of an analysis of affective vocabulary in Russia. First, most of the Russians perceived VR device as a game, movie, or entertainment. Second, fitness trackers were generally perceived as a watch related to health; there were many affective words (e.g., 'life' and 'health') directly related to life. Third, drones were generally perceived as a toy helicopter, and a form of game or entertainment. The vocabulary was collected related to the functional characteristics of the drone (e.g., 'camera', 'flight', 'delivery', and 'observation') and to its appearance (e.g., 'helicopter' and 'toy'). Fourth, most individuals perceived the call taxi service as comfortable and fast services; vocabulary was also generated regarding cost (e.g., 'cheap'). Fifth, most perceived mobile pay as a fast and convenient service using smartphones; vocabulary was produced pertaining to cost (e.g., 'payment' and 'money'). Finally, the virtual currency was generally perceived as a problematic internet currency. Like other IT services, vocabulary was generated regarding cost (e.g., 'currency', 'bank', and 'money'). The unusual aspect of the service group among the Russian sample was that fewer safety-related words were produced than by individuals of other countries; the Russian sample was less sensitive to the safety of products and services.

\subsection{Affective vocabulary comparison and explanation}

\subsubsection{A cultural difference perspective}

First, the individualism scale scores were 91 points for the USA, 20 points for China, 14 points for Indonesia, 18 points for Korea, and 39 points for Russia (Figure 1). According to Hofstede's standards, the USA is an individualistic society, whereas the other countries are defined as collectivist societies. An individualistic society emphasises individual autonomy and self-realisation, in which individuals express their wishes and needs clearly (Hofstede, 1980; Oyserman et al., 2002). Therefore, an individualistic society is more autonomous than a collectivist society. The results of this study also showed that the use of affective vocabulary was largest for American participants as compared with those in other countries (Figure 10).

In the case of the uncertainty avoidance scale, the USA scored 46, which is below the scale midpoint (Figure 1). According to Hofstede (1980), countries with an uncertainty avoidance of less than 50 are more generous with respect to the free expression of opinions on new ideas, innovative products, and technologies. This appears consistent with the large affective vocabulary ratio of the American sample (Figure 10). In the case of Indonesia, the autonomy of expression is low as a collectivist society, but because of the low uncertainty avoidance score, members of this country expressed a high affective vocabulary ratio compared to China and Korea. 
Table 6 Negative vocabulary by product and service
$\mid$

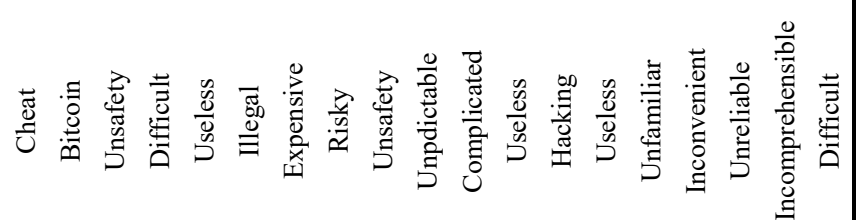

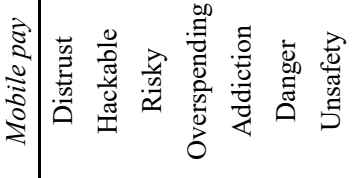

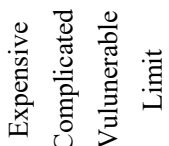

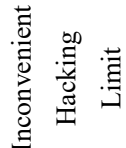

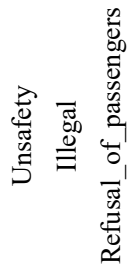

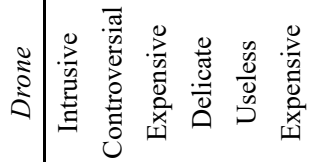

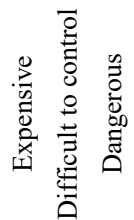

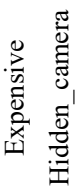

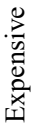

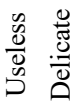

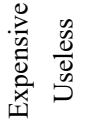

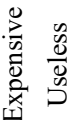

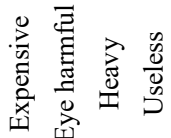

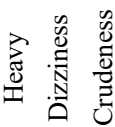

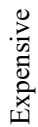
芯 苞

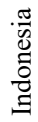
$\stackrel{\mathscr{0}}{\mathscr{0}}$

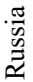


Regarding the indulgence scale, the USA is an indulgent society, as evidenced by its score of 68 points, whereas the other countries are restrained society (low indulgence scores). Hofstede (1980) referred to a society that has relatively weak control over impulses as 'indulgent', whereas a society that has strong control over impulses was termed 'restrained'. While indulgent societies permit the expression of positive emotions, restrained societies are known to have less expression of positive emotions, and stronger tendencies toward pessimism and cynicism (Hofstede, 1980, 2011). In the current study, the proportion of affective vocabulary used by the American sample was is larger than that of other countries (Figure 10), and the number of negative words generated by Americans was smaller than in other countries (Figure 9 and Table 6).

\subsubsection{Positive and negative affective analysis}

There have been numerous studies on the influence of positive and negative aspects of products on consumers, suppliers, and marketers, each of whom buys products and services.

Research has shown that negative information has a greater impact on consumers than positive information (Berlyne, 1954; Skowronski and Carlston, 1989; Henry et al., 2004; Laczniak et al., 2001; Tomczak and Zjawiony, 2018). The products and services covered in the current study tended to be expensive products that are directly connected to money; as such, negative impacts are considered to be much greater. Fiske (1980) and Feldman and Lynch (1988) suggested that negative information is generally more prevalent than positive information, and that negative information is more useful than positive information. Results can be observed in Figure 9, in which negative vocabulary data is less prevalent than positive vocabulary data. Therefore, this study elicited a relatively more negative vocabulary.

Table 6 lists the negative words collected by country, product, and service. Negative information for each product or service can be identified for each country. When introducing products and services by country, it is important to refer to such information. For example, when introducing VR device in China, it is important to emphasise the importance of price reduction and product usability. In Indonesia, 'expensive' appeared for almost all products and services. If a company aimed to market in Indonesia, the effect of price would need to be recognised and addressed. In terms of products and services, there were many negative vocabulary items generated, except for fitness trackers and the call taxi service. In particular, negative vocabulary was frequently mentioned in the case of virtual currency; thus, efforts to improve this negative image are most important.

\subsection{Limitations}

The current study was limited in that it included individuals aged in their ' $20 \mathrm{~s}-$ ' 30 s, who use many IT products and services among various age groups. Future studies should compare results among age groups. Next, because the experiment was conducted in a specific university in each country, it cannot represent each country. In addition, the number of participants was small (30 to 40 persons per country). Future studies should investigate/analyse large samples among various regions within each country. Next, since the results of the Hofstede analysis used in this study vary over time, it is necessary to re-examine such scores on each scale and use these updated values. Finally, Selected IT 
products and services are at different stages of development and application in each country, which can influence the affective vocabulary collected. However, the purpose of this study is to compare and analyse the current affective vocabulary for new products and services in each country. Thus, the national development phase was not considered.

\section{Conclusions}

This study collected affective perceptions of newly introduced IT products and services in 33 Americans, 30 Chinese individuals, 42 Indonesians, 34 Koreans, and 31 Russians. Through positive/negative analysis of the semantic network diagram and vocabulary, the main affective terms relating to each country's IT products and services were analysed. First, for the product group, improving the usability of products was considered important in the USA, where individualism is strong. In the other the countries, wherein collectivism is strong, improving appearance, function, and design was considered important. In all countries, VR device was considered an innovative and positive product, fitness trackers an exercise-related product, and drones toys that deliver products and weapon capabilities. Next, for the service group, this study concluded convenience was most important to the individuals in most countries. There is an awareness of safety and cost issues related to money services in most countries. Koreans were more sensitive to service safety than individuals in China, and Russians were less sensitive to service safety. In Indonesia, prices were considered more important than the safety of products and services. In the USA, there was low awareness of virtual currency. This study identified cultural differences among the five countries in terms of perceptions of IT products and services. Future studies will include a wide range of comparative analyses, including

1 diverse countries that have not been surveyed

2 diverse regions that have not been surveyed in the countries surveyed

3 diverse age groups

4 a comparison of the same country and region, but over time.

\section{Acknowledgements}

This work was supported by the National Research Foundation of Korea (NRF) grant funded by the Korean Government (MSIT) (No. 2018R1C1B5086269 and 2018R1C1B6008848).

\section{References}

Bajpai, A., Jilla, V., Tiwari, V.N., Venkatesan, S.M. and Narayanan, R. (2015) 'Quantifiable fitness tracking using wearable devices', in Engineering in Medicine and Biology Society (EMBC), 2015 37th Annual International Conference of the IEEE, pp.1633-1637.

Bar-Ilan, J. and Peritz, B.C. (2004) 'Evolution, continuity, and disappearance of documents on a specific topic on the web: a longitudinal study of "informetrics", Journal of the American society for Information Science and Technology, Vol. 55, No. 11, pp.980-990. 
Barlow, J. and Maul, D. (2000) Emotional Value: Creating Strong Bonds with Your Customers, Berrett-Koehler Publishers, San Francisco, CA.

Bastian, M., Heymann, S. and Jacomy, M. (2009) 'Gephi: an open source so fitness trackerware for exploring and manipulating networks', in Third International AAAI Conference on Weblogs and Social Media.

Bei, L.T. and Chiao, Y.C. (2001) 'An integrated model for the effects of perceived product, perceived service quality, and perceived price fairness on consumer satisfaction and loyalty', Journal of Consumer Satisfaction, Dissatisfaction and Complaining Behavior, Vol. 14, p.125.

Berlyne, D.E. (1954) 'A theory of human curiosity', British Journal of Psychology, Vol. 45, No. 3, pp.180-191

Borgatti, S.P. (1995) 'Centrality and AIDS', Connections, Vol. 18, No. 1, pp.112-114.

Borgatti, S.P., Everett, M.G. and Freeman, L.C. (2014) Encyclopedia of Social Network Analysis and Mining, UCINET , pp.2261-2267, SAGE, London, UK.

Burdea, G.C. and Coiffet, P. (2003) Virtual Reality Technology, Vol. 1, John Wiley \& Sons, New York.

Cabanac, M. (2002) 'What is emotion?', Behavioural Processes, Vol. 60, No. 2, pp.69-83.

Chaudhuri, A. (1997) 'Consumption emotion and perceived risk: a macro-analytic approach', Journal of Business Research, Vol. 39, No. 2, pp.81-92.

Choe, M., Choi, Y., Park, J. and Kim, H.K. (2019) 'Comparison of gaze cursor input methods for virtual reality devices', International Journal of Human-Computer Interaction, Vol. 35, No. 7, pp.620-629.

Chuang, M.C. and Ma, Y.C. (2001) 'Expressing the expected product images in product design of micro-electronic products', International Journal of Industrial Ergonomics, Vol. 27, No. 4, pp.233-245.

Crosby, M., Pattanayak, P., Verma, S. and Kalyanaraman, V. (2016) 'Blockchain technology: beyond Bitcoin', Applied Innovation, Vol. 2, pp.6-10.

Desmet, P. (2003) 'Measuring emotion: development and application of an instrument to measure emotional responses to products', in Funology, pp.111-123, Springer, Netherlands.

DeWolfe, C., Anderson, T., Vanderhook, T. and Timberlake, J. (2003-2005) History of Myspace Beginnings [online] http://explain.kurikulum.org/_lain.php?_lain=11905 (accessed 30 March 2021).

Drieger, P. (2013) 'Semantic network analysis as a method for visual text analytics', Procedia-Social and Behavioral Sciences, Vol. 79, pp.4-17.

Due, B.L. (2014) 'The future of smart glasses: an essay about challenges and possibilities with smart glasses', Working Papers on Interaction and Communication, Vol. 1, No. 2, pp.1-21.

Efrat, K. (2014) 'The direct and indirect impact of culture on innovation', Technovation, Vol. 34, No. 1, pp.12-20.

Elhai, J.D., Levine, J.C., Dvorak, R.D. and Hall, B.J. (2016) 'Fear of missing out, need for touch, anxiety and depression are related to problematic smartphone use', Computers in Human Behavior, Vol. 63, pp.509-516.

Erétéo, G., Buffa, M., Gandon, F. and Corby, O. (2009) 'Analysis of a real online social network using semantic web frameworks', in International Semantic Web Conference, Springer, Berlin, Heidelberg, pp.180-195.

Fan, D., Li, Y. and Chen, L. (2017a) 'Configuring innovative societies: the crossvergent role of cultural and institutional varieties', Technovation, Vols. 66-67, pp.43-56.

Fan, L., Liu, X., Wang, B. and Wang, L. (2017b) 'Interactivity, engagement, and technology dependence: understanding users' technology utilisation behaviour', Behaviour \& Information Technology, Vol. 36, No. 2, pp.113-124.

Feldman, J.M. and Lynch, J.G. (1988) 'Self-generated validity and other effects of measurement on belief, attitude, intention, and behavior', Journal of Applied Psychology, Vol. 73, No. 3, p.421. 
Fiske, S.T. (1980) 'Attention and weight in person perception: the impact of negative and extreme behavior', Journal of Personality and Social Psychology, Vol. 38, No. 6, p.889.

Furrer, O., Liu, B.S.C. and Sudharshan, D. (2000) 'The relationships between culture and service quality perceptions: basis for cross-cultural market segmentation and resource allocation', Journal of Service Research, Vol. 2, No. 4, pp.355-371.

Hampden-Turner, C. and Trompenaars, F. (2011) Riding the Waves of Culture: Understanding Diversity in Global Business, Hachette, UK.

Han, S.H., Yun, M.H., Kwahk, J. and Hong, S.W. (2001) 'Usability of consumer electronic products', International Journal of Industrial Ergonomics, Vol. 28, Nos. 3-4, pp.143-151.

Harris, P., Rettie, R. and Cheung, C.K. (2005) 'Adoption and usage of m-commerce: a cross-cultural comparison of Hong Kong and the United Kingdom', Journal of Electronic Commerce Research, Vol. 6, No. 3, pp.210-224.

Henry, A., Nigel, P., Linda, B. and Kevin, V. (2004) Consumer Behavior. A Strategic Approach, Houghton Mifflin Company, Boston, MA.

Hofstede, G. (2011) 'Dimensionalizing cultures: the Hofstede model in context', Online Readings in Psychology and Culture, Vol. 2, No. 1, p.8.

Hofsteds, G. (1980) Culture's Consequences, Sage Publications, Beverly Hills.

Hong, J. (2013) 'Considering privacy issues in the context of Google glass', Commun. ACM, Vol. 56, No. 11, pp.10-11.

House, R.J., Hanges, P.J., Javidan, M., Dorfman, P.W. and Gupta, V. (2004) Culture, Leadership, and Organizations: The GLOBE Study of 62 Societies, Sage Publications, Thousand Oaks, CA.

Katsis, C.D., Katertsidis, N., Ganiatsas, G. and Fotiadis, D.I. (2008) 'Toward emotion recognition in car-racing drivers: a biosignal processing approach', IEEE Transactions on Systems, Man, and Cybernetics-Part A: Systems and Humans, Vol. 38, No. 3, pp.502-512.

Kim, D. and Jang, D.H. (2018) 'Expert views on innovation and bureaucratization of science: semantic network analysis of discourses on scientific governance', Science and Public Policy, Vol. 45, No. 1, pp.36-44.

Kim, D.Y., Wen, L. and Doh, K. (2010) 'Does cultural difference affect customer's response in a crowded restaurant environment? A comparison of American versus Chinese customers', Journal of Hospitality \& Tourism Research, Vol. 34, No. 1, pp.103-123.

Kim, H.K., Han, S.H., Park, J. and Park, J. (2016) 'Identifying affect elements based on a conceptual model of affect: a case study on a smartphone', International Journal of Industrial Ergonomics, Vol. 53, pp.193-204.

Kim, H.K., Han, S.H., Park, J. and Park, W. (2015) 'How user experience changes over time: a case study of social network service', Human Factors and Ergonomics in Manufacturing \& Service Industries, Vol. 25, No. 6, pp.659-673.

Kim, H.K., Park, J., Choi, Y. and Choe, M. (2018) 'Virtual reality sickness questionnaire (VRSQ): motion sickness measurement index in a virtual reality environment', Applied Ergonomics, Vol. 69, pp.66-73.

Kim, J.H. and Lee, K.P. (2005) 'Cultural difference and mobile phone interface design: Icon recognition according to level of abstraction', in Proceedings of the 7th International Conference on Human Computer Interaction with Mobile Devices \& Services, ACM, pp.307-310.

Kim, L. and Ju, J. (2019) 'Can media forecast technological progress?: a text-mining approach to the on-line newspaper and blog's representation of prospective industrial technologies', Information Processing \& Management, Vol. 56, No. 4, pp.1506-1525.

Kirkman, B.L., Lowe, K.B. and Gibson, C.B. (2006) 'A quarter century of culture's consequences: a review of empirical research incorporating Hofstede's cultural values framework', Journal of International Business Studies, Vol. 37, No. 3, pp.285-320.

Ko, H., Jung, J., Kim, J. and Shim, S.W. (2004) 'Cross-cultural differences in perceived risk of online shopping', Journal of Interactive Advertising, Vol. 4, No. 2, pp.20-29. 
Kwon, Y.H. (1994) 'Feeling toward one's clothing and self-perception of emotion, sociability, and work competency', Journal of Social Behavior and Personality, Vol. 9, No. 1, p.129.

Laczniak, R.N., DeCarlo, T.E. and Ramaswami, S.N. (2001) 'Consumers' responses to negative word of mouth communication: an attribution theory perspective', Journal of Consumer Psychology, Vol. 11, No. 1, pp.57-73.

Lee, M.C. and Park, J. (2018) 'There is no perfect evaluator: an investigation based on prospect theory', Human Factors and Ergonomics in Manufacturing \& Service Industries, Vol. 28, No. 6, pp.383-392.

Li, N., Brossard, D., Anderson, A.A., Scheufele, D.A. and Rose, K.M. (2018) 'How do policymakers and think tank stakeholders prioritize the risks of the nuclear fuel cycle? A semantic network analysis', Journal of Risk Research, Vol. 21, No. 5, pp.599-621.

Lisetti, C.L. and Nasoz, F. (2005) 'Affective intelligent car interfaces with emotion recognition', in Proceedings of 11th International Conference on Human Computer Interaction, Las Vegas, $\mathrm{NV}$, USA.

McSweeney, B. (2009) 'Dynamic diversity: variety and variation within countries', Organization Studies, Vol. 30, No. 9, pp.933-957.

Mehta, R., Larsen, T., Rosenbloom, B. and Ganitsky, J. (2006) 'The impact of cultural differences in US business-to-business export marketing channel strategic alliances', Industrial Marketing Management, Vol. 35, No. 2, pp.156-165.

Moody, W., Kinderman, P. and Sinha, P. (2010) 'An exploratory study: relationships between trying on clothing, mood, emotion, personality and clothing preference', Journal of Fashion Marketing and Management: An International Journal, Vol. 14, No. 1, pp.161-179.

Moro, S., Pires, G., Rita, P. and Cortez, P. (2020) 'A cross-cultural case study of consumers' communications about a new technological product', Journal of Business Research, Vol. 121, pp.438-447.

Nagamachi, M. (1995) 'Kansei engineering: a new ergonomic consumer-oriented technology for product development', International Journal of Industrial Ergonomics, Vol. 15, No. 1, pp.3-11.

Nagamachi, M. (2016) Kansei/Affective Engineering, CRC Press, Boca Raton, FL.

Oyserman, D., Coon, H.M. and Kemmelmeier, M. (2002) 'Rethinking individualism and collectivism: evaluation of theoretical assumptions and meta-analyses', Psychological Bulletin, Vol. 128, No. 1, p.3.

Panetta, K. (2019) Gartner Top 10 Strategic Technology Trends for 2020 [online] https://www. gartner.com/smarterwithgartner/gartner-top-10-strategic-technology-trends-for-2020/ (accessed 30 March 2021).

Park, J. and Han, S.H. (2013) 'Defining user value: a case study of a smartphone', International Journal of Industrial Ergonomics, Vol. 43, No. 4, pp.274-282.

Park, J. and Han, S.H. (2018) 'A value sampling method for evaluating user value: a case study of a smartphone', International Journal of Mobile Communications, Vol. 16, No. 4, pp.440-458.

Park, J., Han, S.H., Kim, H.K., Cho, Y. and Park, W. (2013a) 'Developing elements of user experience for mobile phones and services: survey, interview, and observation approaches', Human Factors and Ergonomics in Manufacturing \& Service Industries, Vol. 23, No. 4, pp.279-293.

Park, J., Han, S.H., Kim, H.K., Oh, S. and Moon, H. (2013b) 'Modeling user experience: a case study on a mobile device', International Journal of Industrial Ergonomics, Vol. 43, No. 2, pp.187-196.

Park, J., Han, S.H., Kim, H.K., Moon, H. and Park, J. (2015) 'Developing and verifying a questionnaire for evaluating user value of a mobile device', Human Factors and Ergonomics in Manufacturing \& Service Industries, Vol. 25, No. 6, pp.724-739.

Pasztor, A. and Emshwiller, J. (2012) 'Drone use takes off on the home front', The Wall Street Journal, 21 April, Vol. 20 [online] https://www.wsj.com/articles/SB100014240 52702304331204577354331959335276 (accessed 30 March 2021). 
Pullman, M.E. and Gross, M.A. (2004) 'Ability of experience design elements to elicit emotions and loyalty behaviors', Decision Sciences, Vol. 35, No. 3, pp.551-578.

Rhie, Y.L., Lim, J.H. and Yun, M.H. (2017) 'Evaluating representativeness of qualitative text data in identifying UX issues', International Journal of Human-Computer Interaction, Vol. 33, No. 11, pp.868-881.

Scholz, U., Doña, B.G., Sud, S. and Schwarzer, R. (2002) 'Is general self-efficacy a universal construct? Psychometric findings from 25 countries', European Journal of Psychological Assessment, Vol. 18, No. 3, p.242.

Schütte, S. (2005) Engineering Emotional Values in Product Design: Kansei Engineering in Development, Doctoral dissertation, Institutionen För Konstruktions-Och Produktionsteknik.

Seiders, K., Voss, G.B., Grewal, D. and Godfrey, A.L. (2005) 'Do satisfied customers buy more? Examining moderating influences in a retailing context', Journal of Marketing, Vol. 69, No. 4, pp.26-43.

Sheldon, P., Herzfeldt, E. and Rauschnabel, P.A. (2020) 'Culture and social media: the relationship between cultural values and hashtagging styles', Behaviour \& Information Technology, Vol. 39, No. 7, pp.758-770.

Shin, D.H. and Choo, H. (2012) 'Exploring cross-cultural value structures with smartphones', Journal of Global Information Management, Vol. 20, No. 2, pp.67-93.

Shin, J., Park, Y. and Lee, D. (2015) 'Google TV or Apple TV? - the reasons for smart TV failure and a user-centered strategy for the success of smart TV', Sustainability, Vol. 7, No. 12, pp.15955-15966.

Skowronski, J.J. and Carlston, D.E. (1989) 'Negativity and extremity biases in impression formation: a review of explanations', Psychological Bulletin, Vol. 105, No. 1, p.131.

Song, H., Cramer, E.M. and Park, N. (2019) 'Cultural differences in social comparison on Facebook', Behaviour \& Information Technology, Vol. 38, No. 2, pp.172-183.

Stohl, C. (1993) 'European managers' interpretations of participation: a semantic network analysis', Human Communication Research, Vol. 20, No. 1, pp.97-117.

Straus, W. and Howe, N. (1991) Generations: The History of America's Future, Quill, New York.

Swan, M. (2015) Blockchain: Blueprint for a New Economy, O'Reilly Media, Inc., Sebastopol, CA.

Tomczak, P. and Zjawiony, P. (2018) 'The influence of affect on the decision-making process in virtual simulation', International Journal of Human-Computer Interaction, Vol. 34, No. 8, pp.749-758.

Tung, R.L. and Verbeke, A. (2010) 'Beyond Hofstede and GLOBE: improving the quality of cross-cultural research', Journal of International Business Studies, Vol. 41, No. 8, pp.1259-1274.

Van Atteveldt, W. (2008) Semantic Network Analysis: Techniques for Extracting, Representing, and Querying Media Content, Doctoral dissertation, BookSurge, Charleston, SC.

Wei, L. and Kang, J. (2019) 'Employing emotion regulation strategies in tracking personal fitness progress', International Journal of Human-Computer Interaction, Vol. 35, No. 12, pp.1115-1124.

Williams, C. (2014) 'Security in the cyber supply chain: is it achievable in a complex, interconnected world?', Technovation, Vol. 34, No. 7, pp.382-384. 